\title{
Silent No More: A Qualitative Examination of Sexual Violence in St. Lucia ${ }^{1}$
}

Rebecca M. Hayes, Associate Professor

Department of Sociology, Anthropology and Social Work

Central Michigan University

Anspach Hall, Mt Pleasant, MI 48859

Souyenne Dathorne

Positive Reactions Over Secrets and Fear (PROSAF)

St. Lucia, Cap Estate

Gros-Islet, Saint Lucia

Cedric Taylor, Assistant Professor

Department of Sociology, Anthropology and Social Work

Central Michigan University

Anspach Hall, Mt Pleasant, MI 48859

Corresponding author: Rebecca Hayes, hayes2r@cmich.edu

\begin{abstract}
To our knowledge, there has been little research on sexual assault on the island of St. Lucia, with official statistics demonstrating a low prevalence rate. If official statistics are low, governmental and non-governmental organizations can continue to ignore the problem. The current study conducted interviews with survivors regarding their experiences of reporting their sexual violence. The results indicated that survivors were not disclosing to formal agencies. Additionally, participants indicated that they would like to see increased resources for sexual violence survivors on island.
\end{abstract}

Keywords: violence against women, Caribbean, survivors, social support 


\section{Introduction}

Sexual violence is defined as "any sexual act, attempt to obtain a sexual act, unwanted sexual comments or advances" (Jewkes, Sen and Garcia-Moreno 2002, pp.149). Sexual violence may include rape and other forms of assault involving a sexual organ using either physical violence or coercion regardless of the power differential in the relationship (Bott et al. 2005). Violence against women, specifically, sexual violence supports the social norms, traditions and values that underlie the patriarchal culture of male dominance over women's sexuality and the body (Dobash and Dobash 1979, 2004; Jewkes et al. 2002). Social norms such as the objectification of women and victim blaming can manifest and reinforce the gender inequality that legitimize violence against women (Jewkes et al. 2002). There is a connection between the culture, norms and values of a country that support the notion of male superiority regarding authority over female sexuality and the amount of sexual violence (Contreras, J. M, et.al. 2010). From our observations, St. Lucia encourages female sexual objectification within a male dominated society which leads to victim blaming and the underreporting of sexual assault.

St. Lucia, one of the Windward Islands located in the Caribbean is rural and has an approximate population of 166,000 (St. Lucia Statistics 2011). Gender-based violence in St. Lucia is recorded by six agencies: the Royal St. Lucia Police Force (Vulnerable Person's Unit, VPU), the Department of Human Services and Family Affairs, the Department of Gender Relations, The Women's Support Centre (domestic violence), and the St. Lucian Crisis Centre. In 2012, 41 rapes were reported to the VPU, and only 14 adult and child sexual assault cases to the crisis centre. As reported in Sudderth (2013), the Department of Gender Relations in 2010 recorded 69 rapes that were reported to the police with 25 being investigated resulting in 14 arrests. From 2000 to 2012 (except 2011) there were 601 cases of sexual violence reported to the vulnerable persons unit. Of the 601 cases reported 563 were investigated and 176 were closed (Department of Gender Relations 2011). The Department of Human Services and Family Affairs handles cases of child abuse and from 1998- 2010 (except 2008) recorded 817 cases of child sexual abuse (Department of Gender Relations 2011). Anecdotally, these statistics could be misleading as we have personally experienced numerous unreported disclosures of sexual violence from women on the island. It is important to note that in official statistics reported above there are missing years. When we asked why there was no data for 2011 we received no explanation. Nevertheless, these numbers are not surprising as in other areas in the Caribbean and Latin America, only approximately 5\% of women report to the police (Contreras et. al. 2010). One of the potential contributing factors to low reporting rates may be lack of awareness of what constitutes sexual violence.

Different definitions between agencies regarding what constitutes sexual violence are not surprising, yet likely confuse information across agencies as well as potential reporters of sexual violence. While we do not have access to all of the exact definitions used by different agencies, the definitions within the Vulnerable Persons Unit appear to be confusing. In 2000-2004 rape 
and incest were not listed as a crime against the person, but as a crime against public morality. Additionally, it was only in 2009 that attempted rape was recorded, with 11 cases reported and 3 closed (Department of Gender Relations 2011). Recent research on official agencies in St. Lucia reported that they believed that there are many cultural barriers to disclosure, such as victim blaming and lack of confidentiality due to the small size of the island (Sudderth 2013). The question of who survivors are reporting to (if at all) and how they are being treated lead to this projects conception. To our knowledge, there were no available studies on sexual violence in St. Lucia. Therefore, we chose an exploratory, inductive method to begin the investigation.

\section{Methodological Approach}

Plummer and Young argue that in order to adequately protect human subjects it is imperative to give them a voice (e.g. grounded theory) (Evans 2013). The grounded theory approach encourages researchers to listen to the subjects experience and to draw common themes from the descriptions that participants share (Evans 2013). Similarly, feminist standpoint theory argues that the inclusion of the female voice allows for a more accurate perspective on how women are affected (Hartstock 1983). Men's perspectives, through the lens of male privilege, will differ from a woman's perspective. The story and unique perspective can only be gathered directly from the group being affected, which is why grounded theory ardently suggests that a voice be given directly to those being studied. Historically, the dominant groups' viewpoint is often adopted and therefore, shapes responses to social problems such as sexual assault. Without excluding or devaluing the work and opinions of males in the field of sexual violence, it is also imperative to acknowledge the voices of women who predominately have been the ones to experience said violence.

Sexual violence, predominately a violence against women issue, needs to be juxtapositioned within the context of the oppressions that women deal with on a daily basis. St. Lucia's is in a post-colonial era that has cultural considerations that influence the lived experience of women's oppression. Social characteristics (race, class and religion) also need to be examined along with being female in a male-dominated society (Collins 2000). Additionally, the social location of the reviewer is paramount to the integrity of the interviews.

The methodological debate between feminist standpoint versus feminist empiricism (see Campbell 1994) is seemingly similar to the debate regarding qualitative and quantitative research in the social sciences. That is, is it possible for a researcher to stay objective when engaging with participants and indeed is objectivity even necessary? Due to limited space, we will not engage in that debate in this manuscript. However, it is important to note that the interviewers gender, race, class were all taken into account during this study. Specifically, all but two of the interviews were conducted by St. Lucian women in order to create a more comfortable and supportive environment for the participants. The women were all trained victim advocates in order to recognize emotional distress even in subtle forms. They were also trained as 
interviewers to maintain an objective stance and supportive, safe environment for participants. The interview schedule was also important to this conversational and supportive environment.

An open-ended interview schedule was used that allowed the survivor to relay their experiences in an open forum where they were in control. According to Reinharz (1992), semistructured interviews have become the main method of feminist research. Additionally, Starzynski et al. (2005) moved from quantitative surveys to qualitative interviewing because interviews provide more context. The intention here is to set up a long term research agenda to address sexual violence prevention and response in St. Lucia. Therefore, context matters.

\section{Design}

A non-probabilistic, purposive sample with semi-structured interviews was used for the present study. Participants for this research study were either recruited by word of mouth or responded to a bi-weekly article that one of the authors writes regarding sexual violence. During the study period, approximately 25 women came forward and 13 interviews occurred. Four women agreed to interviews even so far as setting up a time and then did not show up. This is not surprising given the nature of the topic, additionally culturally no shows and tardiness is common. There was no recourse if women chose not to participate and some of them still used the resources of PROSAF-Surviving Sexual Abuse in the Caribbean.

Similar to Guest, Bunce, and Johnson (2006), data saturation was met within the 13 interviews conducted, with thematic elements being obvious within the first six interviews. This is likely because the interview schedule was relatively short with the majority of interviews lasting around 30 minutes. The questions were open-ended with probes, yet straightforward. For example, "After the assault did you contact someone? If yes, who? What's your relationship with that person? Can you describe your experience with speaking with this person? How did they respond?" Not all questions were asked as they were already answered. Finally, in order to engender anonymity and honesty in responses, we did not collect any demographic statistics.

Each semi-structured interview included an interviewer and a victim advocate on stand-by in the case of a crisis. The interview schedule consisted of questions that sought information about the feelings and reactions to the assault disclosure, the impact that the disclosure had on them, and what resources they would like to see for survivors. They were conducted in-person in 2012-2013. They were audio-recorded with the interviewee's explicit permission, with one interview being hand written. A self-chosen pseudonym was used for one of the interviewees, all others chose not to be named. The recorded interviews were uploaded to a secure server and then deleted from the recorder. Each interview was transcribed and then checked again for errors.

\section{Theme Coding}

There were two levels of coding by independent coders. The first level of coding consisted of each coder reviewing the transcripts and coding for themes underlying each question and 
identifying overall themes. Once overall themes were agreed upon the second coder analyzed the transcripts once more and wrote up the findings. The following umbrella research questions are addressed below: Who did the survivor talk to after the assault? What was that initial person's reaction? Do they regret telling that person? What types of resources are necessary for survivors?

\section{Findings}

To begin, of the 13 interviewees only one officially reported their assault. The findings of this study reflect survivors' experiences with sources of formal support (e.g. police, counseling services) and informal support (e.g. friends and family) in the aftermath of their sexual assault. More specifically the findings reflect survivors' responses to questions surrounding who they talked to after the assault, the reaction of the person(s) they talked to, and whether they would seek help from these sources again. Additionally, the findings reflect perceptions on what specifically is needed for respondents to heal and what is needed overall for survivors of sexual assault in St. Lucia.

\section{Informal Support}

All twelve survivors sought some form of support from informal (e.g. friends and family) sources as opposed to formal sources (e.g. police, counseling services). The type of informal support sought seemed to be contingent upon the relationship closeness and availability of the person(s) sought for support. When one survivor was asked why she told her parents she responded:

"I decided to tell them because I felt like for me to be carrying this on for so many years maybe I needed some action and I felt like maybe they would be the best people to actually make a move I don't know to monitor my uncles and my cousins and be sure that they are not doing it to anyone else or I don't know something."

However, disclosure was not necessarily contingent on familial ties. In some situations a parent was the initial person contacted after the assault, but in other cases extended family members, or friends were the first to be notified. In certain cases friends received the initial disclosure because of their availability as well as a fear or uncertainty of how family members would react. Overall, the respondents point to trust, access and a feeling of closeness as the main criteria for disclosure rather than mere familial ties. One survivor, in the immediate aftermath of her sexual assault explained why she first contacted a friend who happened to be a police officer:

"We were friends we were close friends and um I'd spoken to him a few hours earlier so when it happened that was the first person that came to mind though he wasn't anywhere around um I figured let me call him and let him know and [name] we went to school together and being that I was visiting my sister in town where it happened he was the closest person to me there so I called him as well." 
In the above case it was the fact that it was a friend not because the person was a police officer that initiated the disclosure. Overall, survivors were more likely to seek informal sources of support based on the sentiment that family or friends were less likely to "judge" and more likely to receive more positive reactions and emotional support as compared to sources of formal support such as the police and counseling services. However, disclosing sexual assault to family and friends did not guarantee positive and helpful responses to survivors.

Survivors indicated a variety of responses from informal support sources. In four cases confidants were fairly positive and refrained from judging the survivors. In these cases survivors felt that they were listened to and believed. Further, they felt that they received what they needed and would disclose their assault to family or friends again. The narrative of one survivor indicated support that was responsive to her needs, when she disclosed being sexually assaulted to a friend. When asked to describe the experience of telling her friend she replied:

"Oh it was rather emotional like I was crying sometimes and she would be like alright you will be okay I was like she understands what I'm going through and she can be there pray and try to convince myself that I am not rubbish...she made me feel good about myself. She told me I was being very careful with men I associate with, which is true."

The respondent went further on to express gratitude for not being judged even though the sexual assault occurred at the tail end of a six month long abusive relationship with a male partner. Her friend's response was helpful not only because it displayed empathy but also because it lacked "judgment":

"Just someone to tell me that we all make mistakes and that I'm an okay person I'm not a bad person just because I made some bad decisions. I don't deserve people judging me...”

Another survivor noted that her boss was her initial source of support:

"Well my boss, it wasn't them it was the woman, well she's a, she was more of, she's easier to talk to, and she in spite of that whole relationship between boss and you know staff she has a heart..."

Five survivors perceived the responses of family and friends as negative or unsupportive. For instance, three survivors, were accused of "overreacting", or bringing the assault on themselves and that they should "get over it", "move on", or "to stop making excuses". Some family members expressed embarrassment. One survivor after confiding with a cousin was given a response that belittled her experience, suggesting that what she experienced wasn't a sexual assault per se, but rather a normal part of development. She explains:

"I told another older cousin and she said to me that, oh that's normal that's just how those boys play that's just how they ya know that's what boys do, that's just what boys and girls do" 
Although there were responses that were deemed unhelpful by survivors, none were done with any maliciousness. In fact it could be argued that there is some level of difficulty in classifying some of the responses as either totally positive or negative. Indeed some of these responses had elements of both compassion and 'blaming the victim'.

One respondent described her father's reaction:

"Oh he, kinda, he kinda thought for a minute umm cause I let out everything, I didn't just tell him the emotions came out and umm I think for a minute there it felt like he was a bit guilty, knowing that he was there and it took me almost 11 years to tell him. His best friend was there when I told him and I think they were both just shocked but they didn't really...they responded like, they had normal emotions like they were sad and everything but after that, that was it."

In addition to expressing shock the survivor's father was unable to offer much more support:

"I expected him to ask questions, he didn't really ask who it was, he didn't ask umm when or you know, maybe understand why I am the way I am. You know he just kinda...I don't blame him ummm, just because he, I don't know, it just happened, and he figured ya know its all in the past now so..."

Even though sources of informal support are well intentioned, survivors' responses suggest that these sources lack the know how to adequately help a loved one cope with sexual assault. Grief, anger and guilt are common emotions displayed by the family. One survivor recounts her father's reaction:

"So with my dad there was extreme guilt and anger umm I guess his baby had been violated so much and he had no idea. Umm I guess there was a lot of confusion. It did, it did put a strain on everyone's relationships in the house for a bit because they felt there was so much they just didn't know and they just kept going on and on about that, not understanding like what it takes out of somebody to tell this type of thing so..."

While such displays of emotion and sympathy are unsurprising, this did not equate to any meaningful action on the part of the family. This paralysis is a source of frustration for both families and survivors.

"...I guess in a way they felt frustrated ya know. So umm yeah I wish that they had just listen and not taken it so personally made me guilty cause they didn't. I guess they didn't realize how guilty they made me feel until one day I had to explode and tell them look this is not you, like you're making me feel worse you know and they understood."

Some survivors seemingly know the limitations of their sources of informal social support. Knowing the emotional trauma their family and friends may go through, some survivors 
opt to deal with the emotional trauma of sexual assault in silence in an effort to protect their family and friends from pain. Spicy articulated this point when asked why she chose to discuss with the interviewer the circumstances of her sexual assault:

"Its something that it never goes away and the pain is always there and as much as you want to talk about it you want to protect your family members or your friends from that whole thing cause you know what it has done to you...I don't think they will ever able to deal with it so more of a protection thing for my family for my friends."

Arguably, survivors like Spicy are doubly burdened. They often feel responsible for the reactions and extreme emotions of loved ones while simultaneously coping with their own trauma. Typically, survivors expressed various levels of disappointment, and emotional distress as a direct result of unsupportive and negative responses from family members and friends. When asked if she experienced any negative emotions after she felt her family was not there for her she responded:

"I was suicidal um for I would say two and a half years I was very much suicidal. Um I didn't feel loved I felt everything that you all your values and morals are ripped away in just that one night and you cant ever get it back and even though you try it is so difficult because of so many things happening around you. Um so mostly self-love is quite difficult...um I've come a long way but even sometimes that negative energy kicks in and I have to try to get away from that. I can still say sometimes still the suicidal thoughts come depending on what happens um if somebody depending on, mostly my mom if she says something that's hurtful then the suicidal thoughts will come and I have to kinda deal with it on my own."

Interestingly the disappointment and hurt experienced was sometimes tied to how close the survivor was to a family member or friend. When another survivor was asked how she felt after her parents failed to adequately support her after her assault, she replied:

"No I felt, the disappointment I normally feel when I bring anything to parents like they aren't really in corner and they don't really support me and I definitely felt very let down but it was honestly expected."

Yet another survivor expressed being hurt, a likely product of being betrayed by her own mother:

"Well I was upset I was okay that person didn't listen to me who else can I tell. I felt like maybe she was putting him over me and not really listening to what I was saying and that she probably loved him and not me."

The majority of survivors sought some form of social support from informal sources such as friends and families. Overall the narratives suggest that these informal sources of support are ill equipped to effectively help the survivors cope with their sexual assault. 


\section{Formal Support}

Three respondents expressed reservations towards help seeking from formal sources of support. When one survivor was asked if she ever went to law enforcement she replied:

"Never, especially not in St. Lucia. I feel like you cant really trust these people and um I don't think they would handle it professionally and um that would end up causing more repercussions for me so I just avoided that."

In fact, a significant obstacle to seeking help from the police was the issue of confidentiality. Participants reported concern that the sexual assault would be made public. The survivors who did seek assistance from the St. Lucian police indicated that it was not helpful. When asked about their experiences with the police, survivors used adjectives such as "unprofessional", "judgmental" and/or expressed fears that the police would mistreat, or not believe them. One survivor recounted her experience:

"Because of how I was treated in the interviewing process, they made me feel like I was the victim like I did something wrong and um its kinda I look back on it sometimes and I wonder who does that, you at the police station you went in to give a statement who brings the individual who rapes you just an arms length away from you and so they could tell the you know, the officer who's taking the statement everything that happens and the guy who raped you is right there who does that?"

This harrowing experience reflects the fears of many of the survivors in the study who point to the police creating a hostile, judgmental environment, which lacks confidentiality. Additionally, two respondents suggested that the manner in which the initial investigation is conducted inherently assumes that a victim of sexual assault is lying. Shelly, articulates this when she was asked about her experience with the police:

" first of all doing everything in a speedy manner and not looking at you, like you brought it upon yourself... and they would say subtle things to you and I'm not sure if its their line of questioning...their line of questioning makes you feel ok you brought it upon yourself...while I was giving my statement they kept asking the same things over and over and over like okay I told you that already. Why do you have to ask it to me again?...and when you feel like they are taking the statement they are not actually writing down anything ya know they are not writing cause in my case if I had kept looking and they guy was just there... he was kinda like drawing whatever stuff on it. And the lady the following day she took the statement but she didn't seem like she was interested like okay whatever I cannot."

One survivor utilized her high school counseling services but did not see it as helpful. The survivor felt that the high school counselor listened to her but seemingly was unable to give any meaningful assistance. She added that the information shared was “probably for the counselor's 
own benefit" rather than hers. On two occasions young survivors informed their teachers. However, respondents revealed that teachers also lacked the skills and resources to help survivors cope. Instead, they were likely to just report the incident to superiors or the survivor's parents. One survivor, Spicy, suggested that although there may be organizations in place for those who have been sexually abused, in St. Lucia, "you barely hear of a rape crisis center".

Though friends and families were typically seen as more desirable sources of support, overall participants reported that both formal and informal sources of support were not very helpful. Family, friends and the police all at times provided similar negative responses that were victim blaming and judgmental. Although the function of formal support sources is to provide meaningful assistance (counseling, punishment, arrest), none of the interviews indicated that assistance was forthcoming.

\section{Resources}

All twelve of the respondents had ideas in terms of what was needed in St. Lucia for survivors of sexual assault. While the arrest and imprisonment of perpetrators was voiced, three survivors indicated a dire need for police officers to be more adequately trained in dealing with sexual assault. For instance police officers need to "not come off as though they [the victims] are lying". One survivor called for increased awareness among all professionals who may directly handle cases of sexual assault such as ministers, teachers lawyers and healthcare providers. Others pointed to the need for access to a space where mental health professionals "who will not judge" are available. For example one survivor commented:

"I'd like to know that we have a designated spot where people are qualified so that in the event that you want somebody to talk you know that you can go here and that people will listen and you don't have to worry about being judged or not believed but you know, supported... so It'd be nice to have a specific center for that."

Another survivor adds:

"I would like to see they do a place where they could go to get the help they need and it's like nobody has to know... you need to know that wherever you go that nobody else will find out cause most of us are pretty ashamed of it, we don't really want nobody to know there are lots of rapes in St. Lucia but none of them recorded..."

The responses suggest that formal sources of support are needed in St. Lucia, but there is apprehension in utilizing them because of a lack of confidentiality. The responses of some of the survivors indicated an awareness that the lack of effectiveness of the police and other formal sources of support, is occurring in a wider social context. One survivor for instance pointed to widespread myths, which inform many attitudes and beliefs regarding what constitutes sexual 
assault:

"Generally I don't think people take these things seriously its just a thing you see on lifetime or on the movies and if a girl says she is raped if its by her husband or her boyfriend but that's a man. Its not possible because no is no. Whether or not I'm married to you doesn't mean I have to give you sex its ya know it is your body and you can decide to say no. So I mean before anything can be done in terms of programs, attitudes would have to change and the only way to change is through information."

One respondent went a step further when asked about what sexual assault survivors in St. Lucia need.

"I think that it wouldn't have to start with the victims, I don't think its starts with the victims. I think it actually starts with these sick minds. Try to make them understand what they're really doing and not just what they are doing at the time, not just the physical but what they do long term. I want to see something that makes people realize what they are doing, its not just about your pleasure, your sick pleasure at that time but what you really do to people."

Essentially, she is articulating how the focus on sexual assault needs to be reoriented to perpetrators of sexual violence and not on the victims. In a society in which many issues of sexuality are "taboo", this still would require survivors to speak out.

"I want them to be strong enough to come forward and discuss it. I think the big battle is yes I know it is hard discussing it but I think the big battle is keeping it in all this time and I think that if they are able to come forward and discuss it and discuss with people that have been there and overcome the bad dreams and the feeling that you aren't a real person anymore not being able to have a sense of normalcy in everyday activities with people you love... I want them to not feel trapped in their own bodies ya know?"

In light of the failed capacity of formal and informal sources to positively support survivors of sexual assault in St. Lucia, five respondents expressed either uncertainty with how they would heal, or expressed determination to help themselves,

"To be honest, I don't think it is possible for me I don't see it, I don't see it, I don't see it in my future. I mean I try to be realistic, but there are some days that um, I'm totally alright and there are some days I'm just literally all over the place...I need to do something but I just don't know what is right now and I just try not to think about it..." 


\section{Conclusion}

The present study was exploratory in nature, and therefore the results above are meant to tell the story from the vantage point of the survivor. The major take-away here is the need for confidentiality on the island. Multiple signs point to this being the major over-all theme: (1) Women were reluctant to come forward. Even when wanting to discuss these issues almost all expressed fear of others finding out. (2) Reluctance to report to police. (3) When asked about what resources are needed they specifically talked about a safe place with confidentiality. Culturally, this small, rural island may make survivors feel that there is safety in disclosure. That if they do tell everyone will know, especially their attacker. Unlike larger, more urban spaces the likelihood that they will see their attacker again is not only likely, it is assured. What this research provides are directions for future research. The themes presented can be used to create a quantitative survey to be disseminated to a larger sample of people. Additionally, the present research could be expanded upon by the inclusion of both males and females. The reactions of support providers indicate a potential lack of education on sexual violence. Future research directions could also examine not only the prevalence but the knowledge of sexual assault issues and resources. Overall, we think this research supports the notion that survivors of sexual violence need to continue to be provided a chance to speak.

\section{Endnote}

${ }^{1}$ Portions of this research were presented at the 2012 and 2013 meetings of the American Society of Criminology. The authors would like to thank, Keiondra Grace and Rebecca Abbott for their invaluable assistance in transcribing the data. 


\section{References}

Campbell, R. (1994). The virtues of feminist empiricism. Hypatia, 9, 90-115, http://dx.doi.org/10.1111/j.1527-2001.1994.tb00111.x

Collins, P. H. (2000). Black Feminist Thought: Knowledge, consciousness, and the politics of empowerment. ( $2^{\text {nd }}$ ed.). New York, NY: Routledge.

Contreras, J.M., Bott,S., Guedes,A., Dartnall,E. (2010) Sexual Violence in Latin America and the Caribbean: A Desk Review. South Africa: Sexual Violence Research Initiative.

Department of Gender Relations. (2011). Reports from Royal St. Lucia Police Force: The Vulnerable Persons Unit, Family Courts and Crisis Centre. Castries, St. Lucia.

Division of Human Services and Family Affairs. (2010). Social Issue: Child Abuse, JanuaryDecember, 2010. Report for Department of Gender Relations, St. Lucia.

Dobash, R.E. and Dobash, R. P. (1979). Violence against Wives. New York: The Free Press.

Dobash, R. P. and Dobash, R. E. (2004). Women's violence to men in intimate relationships: working on a puzzle. British Journal of Criminology, 44, 324-349, http://dx.doi.org/10.1093/bjc/azh026

Evans, G. L. (2013). A novice researchers first walk through the maze of grounded theory: rationalization for classical grounded theory. The Grounded Theory Review, 12, 37-55.

Guest, G., Bunce, A. \& Johnson, L. (2006). How many interviews are enough? An experiment with data saturation and variability. Field Methods, 18, 59-82, http://dx.doi.org/10.1177/1525822X05279903

Hartstock, N. (1983). The feminist standpoint: Developing the ground for a specifically feminist historical materialism. In S. Harding and M.B. Hintikka (Eds.), Discovering reality (pp. 283-310). Boston: Ridel.

Jewkes, R., Sen, P., and Garcia-Moreno, C. (2002). Sexual violence. In Krug E., Dahlberg, L., Mercy, J.A., Zwi, A.B., Lozano, R. (Eds.), World Report of Violence and Health. Geneva (pp. 147-174). Switzerland: The World Health Organization.

Morrison, A., Ellsberg, M., and Bott, S. (2004). Addressing gender-based violence in the Latin American and Caribbean Region: A critical review of interventions. New York: World Bank Publications.

Reinharz, S. (1992). Feminist Methods in Social Research. New York: Oxford University. 
Royal St. Lucian Police Force (2000-2012). Retrieved from http://www.rslpf.com

Starzynski, L.L, Ullman, S.E., Filipas, H.H., and Townsend, S.M. (2005). Correlates of women's sexual assault disclosure informal and formal support sources. Violence and Victims, 20, 417-432, http://dx.doi.org/10.1891/vivi.2005.20.4.417

St. Lucia Central Statistics Office, (2011).

http:/www.state.gov/documents/organization/160172.pdf

Sudderth, L.K. (2013). Services for survivors of sexual assault in St. Lucia. Report submitted to PROSAF. 